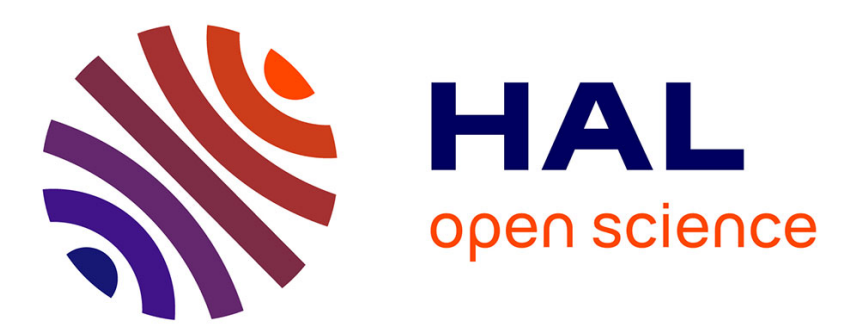

\title{
Self-cleaning, maintenance-free aerosol filter by non-thermal plasma at atmospheric pressure
}

\author{
J.-P. Borra, N. Jidenko
}

\section{To cite this version:}

J.-P. Borra, N. Jidenko. Self-cleaning, maintenance-free aerosol filter by non-thermal plasma at atmospheric pressure. Journal of Hazardous Materials, 2012, 235-236, pp.237-245. 10.1016/j.jhazmat.2012.07.055 . hal-03216716

\section{HAL Id: hal-03216716 \\ https://hal.science/hal-03216716}

Submitted on 4 May 2021

HAL is a multi-disciplinary open access archive for the deposit and dissemination of scientific research documents, whether they are published or not. The documents may come from teaching and research institutions in France or abroad, or from public or private research centers.
L'archive ouverte pluridisciplinaire HAL, est destinée au dépôt et à la diffusion de documents scientifiques de niveau recherche, publiés ou non, émanant des établissements d'enseignement et de recherche français ou étrangers, des laboratoires publics ou privés. 
Self-cleaning, maintenance-free aerosol filter by non-thermal plasma at atmospheric pressure

\title{
N. JIDENKO and J.-P. BORRA
}

Equipe Décharges Electriques et Aérosols du Laboratoire de Physique des Gaz et des Plasmas (UMR 8578 CNRS - Univ Paris-Sud Orsay, F-91405)

Supelec, Plateau Moulon, F-91192 Gif-sur-Yvette, France

e-mail: nicolas.jidenko@u-psud.fr

\begin{abstract}
.
Two lab-scale self-cleaning filters based on Dielectric Barrier Discharges in air at atmospheric pressure have been developed and tested. Experimental results on aerosol removal by charging and electro-collection are presented versus plasma and hydrodynamic parameters for monodisperse aerosol from $20 \mathrm{~nm}$ to $1.2 \mu \mathrm{m}$. For classical atmospheric aerosol, the average mass and number filtration efficiencies exceed $95 \%$ and $87 \%$ respectively in the most penetrating size range $(100-700 \mathrm{~nm})$. The frequency of the applied voltage controls the amplitude of the oscillation of charged particle and can be adjusted to favour either filtration or cleaning. Low frequency $(1 \mathrm{kHz})$ is suitable for electro-collection, while high frequency $(60 \mathrm{kHz})$ is favourable for filter cleaning. Electrical characterization and filter efficiency are two indicators of the filter loading. The durations of both filtration step at maximal efficiency and cleaning step depends on the deposited mass, the surface input power and subsequent dielectric surface temperature.
\end{abstract}

Keywords: aerosol, filtration, non-thermal plasma, dielectric barrier discharge

\section{Introduction}

The filtration of particulate matter from a gas stream is a long-established and important process. The design of filters is a compromise between filtration efficiency and operational cost depending on the properties of aerosol (size and concentration) and gas flow rate to be filtered. Due to their sub-micron size, the aerosol penetrates into the slow-clearing regions of the lungs. It is thus necessary to remove these particles with maximum efficiency while keeping the filter pressure drop to a minimum. Most filters induce a pressure drop across the filter that increases with the filter loading and thus requires frequent maintenance. Different options have been developed to limit this drawback [1] such as mechanical or hydrodynamic filter cleaning of fibrous filter [2], and electrical assisted fibrous filters. Besides, classical electrostatic precipitators induce low pressure drop [3]. Nevertheless, all these filters still require maintenance. The aim of this paper is to prove that filters with low-pressure drop and without maintenance can be developed based on non-thermal plasmas at atmospheric pressure. The ionizing and reactive properties of this type of plasma are used to respectively charge the aerosol for initial electro-collection and to remove the organic aerosol collected on the surfaces.

In non-thermal plasma, free electrons gain energy from an imposed electric field and lose energy through collisions with neutral gas molecules. A large fraction of the energy is used to dissociate gas molecules creating ions and active chemical species (excited atoms and molecules as well as free radicals) [4-7]. 
The dielectric barrier discharge (DBD) generates non-thermal plasma at atmospheric pressure. In DBD, two electrodes are separated by a gas space with at least one dielectric material in the gap. The surface polarization of the dielectric barrier prevents the formation of spark but involves an alternative power supply (typically a few $\mathrm{kV}$ at $50 \mathrm{~Hz}$ to $1 \mathrm{MHz}$ ) [5-9]. DBD has been applied to the electrostatic charging of aerosol by collection of gaseous ions [10-12] and to the collection of aerosol particles [13-16].

The mechanisms of aerosol charging by collection of gaseous ion and the related charging laws (diffusion and field charging) are well defined [4]. "Fine" particles, with diameter $\left(\mathrm{d}_{\mathrm{p}}\right)$ smaller than $100 \mathrm{~nm}$, are mainly charged by the diffusion of ions to the surface of the particle. "Coarse" particles $\left(d_{p}>0.6 \mu \mathrm{m}\right)$ are charged by the drift of ions on the field lines intersecting the surface of the particle. In the intermediate size range $(0.1$ to $0.7 \mu \mathrm{m})$ particles are charged by combined field and diffusion charging, but both mechanisms are less efficient. This size range is referred as the most penetrating particle size (MPPS).

For a given particle size, the particle charge level depends on charging conditions defined by the product of ion density $\left(\mathrm{N}_{\mathrm{i}}, \mathrm{m}^{-3}\right)$, transit time in this density $(\tau, \mathrm{s})$ and the electric field (E, V.m ${ }^{-1}$; only for the field charging mechanism). These charging laws have been validated in quasi-stationary ion densities, especially in DC corona discharges with wires and needle, as active electrodes. The final number of charges per particle depends on the particle size and on the charging conditions, including the mean $\mathrm{Ni} \cdot \tau$ product, related to the time integration of ion densities seen by the particle, along its trajectory.

In the DBD filter, each filament of discharge can be considered as a local and brief ion/electron source leading to expanding ion cloud. Charging conditions are thus transient, with varying electrical field and charge densities along the particle trajectory [17].

The feasibility of a self-cleaning aerosol filter using DBD will be presented. The main objective is to show that the DBD filter is able to remove the aerosol previously collected on the dielectric surfaces in the filter. This implies the use of the filter in two successive steps: a collection step at low frequency and a cleaning step at high frequency.

Two lab-scale DBD filters have been compared in terms of aerosol filtration efficiency and filter cleaning [18]. Tests were carried out under a range of DBD operating conditions (voltage amplitude, frequency) using monodisperse aerosol (Geometric standard deviation of the size distribution below 1.2) with tuneable concentration and size.

The first section of the results deals with the aerosol filtration efficiency in the DBD filters, the second with the charge and the electro-collection efficiencies and the third with the cleaning of the DBD filters. Finally, the discussion addresses the mechanism of filter cleaning, the influence of the phase (liquid or solid) of the aerosol and the comparison of the two filters for organic and mineral aerosols.

\section{Experimental setup and methods}

The experimental set-up (depicted in Fig. 1) may be divided in three parts: aerosol production, DBD filter and aerosol characterisation.

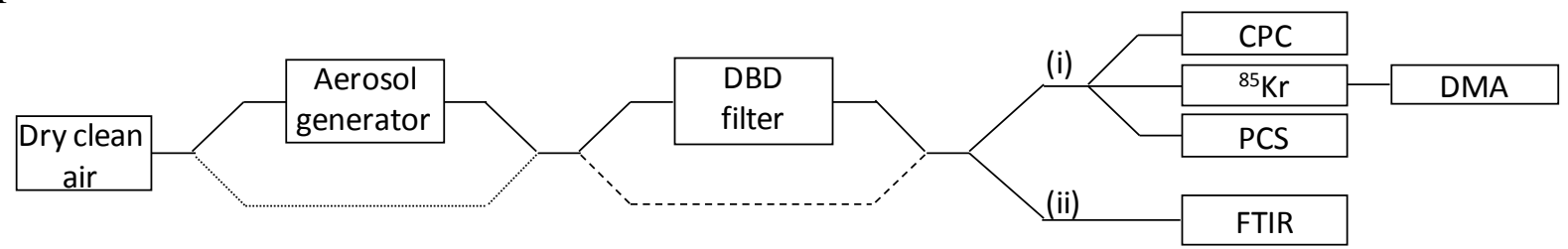

Fig. 1. Schematic diagram of experimental system 
The design and the electrical characterization of the DBD filter, as well as the production and the characterization of the aerosol are described in the following paragraphs.

Whatever is the environmental application based on non-thermal plasma to be developed, the control of the properties of both plasma and pollutant is required to understand the coupling of the physical processes involved and to optimize the plasma reactor and the operating conditions.

\subsection{Dielectric barrier discharge filters}

\subsubsection{Design}

Two DBD filters have been designed (as described in Fig. 2) and tested. In both filter, the size of the electrodes is $1 \times 3 \mathrm{~cm}^{2}$, the gap width is $1 \mathrm{~mm}$. The dielectric materials are alumina for the "alumina filter" and cordierite for the "cordierite filter".

(a)

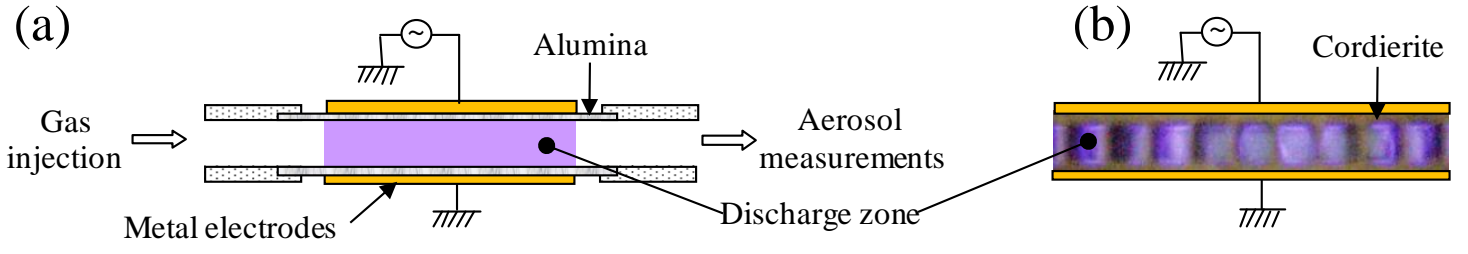

Fig. 2. DBD filters: (a) alumina plane-to-plane arrangement (b) photo of the DBD honeycomb cordierite

The alumina filter was made with two parallel alumina plates (purity 96\%, thickness $\mathrm{e}=0.55 \mathrm{~mm}$, relative permittivity $\varepsilon_{r} \sim 9$, surface roughness $\left.\sim 0.08 \mu \mathrm{m}\right)$. The cordierite filter was a single stage of a cordierite monolith with honeycomb structure (thickness of the walls $\mathrm{e} \sim 0.5 \mathrm{~mm}, \varepsilon_{\mathrm{r}} \sim 5$, and surface roughness $\sim 5 \mu \mathrm{m}$ ) used in diesel exhaust treatment. The square channels of $1 \mathrm{~mm}$ impose the discharge gap. The width of the electrodes $(1 \mathrm{~cm})$ corresponds to 9 pores.

\subsubsection{Plasma characterization}

The DBD filters were supplied with a sinusoidal high voltage. The frequency could be adjusted from 0.75 to $60 \mathrm{kHz}$ with a maximum peak-to-peak voltage of $20 \mathrm{kV}$.

In air, at atmospheric pressure, DBD occurs as thin and brief filamentary discharges (duration: a few 10's of ns, diameter a few $\mu \mathrm{m}$ ) homogeneously distributed over the dielectric surface $[19,20]$. In the cordierite DBD, the dielectrics walls (perpendicular to the electrodes) lead the filamentary discharge coupling volume and surface discharges (cf. Fig. 2b).

Current measurement with an oscilloscope is used to get data on filament characteristics as well as on the temporal distribution of the filaments. Indeed each filament induces a current pulse in the external circuit. Current and voltage were thus measured with an oscilloscope and treated as described in [21]. In both polarities, filaments are identical due to the symmetry of the DBD. The operating conditions in which all the filaments can be considered identical have been identified. Using smooth parallel dielectric surfaces in a given DBD arrangement, the electrical characteristics of filamentary discharges in air do not vary more than $25 \%$ whatever the voltage and the frequency between 1 and $60 \mathrm{kHz}$ are [21]. The frequency of the applied voltage controls the repetition rate of the filament at the same place whereas the applied voltage controls the spatial density of filaments.

The input power, calculated from the product $u(t) \cdot i(t)$ time integration (with $u(t)$ the instantaneous applied voltage and $i(t)$ the instantaneous current is the external circuit) is presented versus applied voltage in Fig. 3 for the alumina and cordierite at $60 \mathrm{kHz}$ in red and at $1 \mathrm{kHz}$ in blue. 


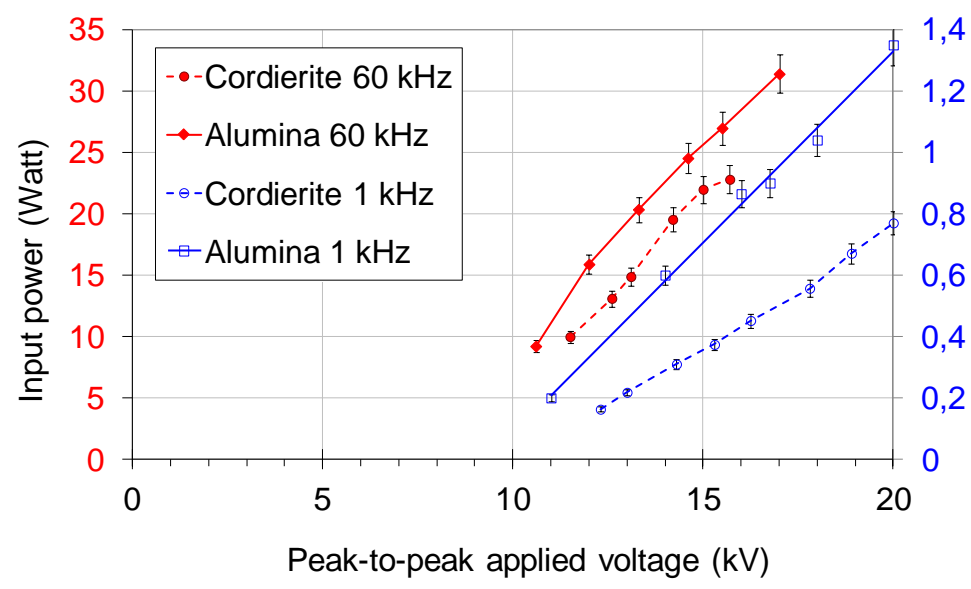

Fig. 3. Input power versus applied voltage for the cordierite and alumina DBD filter at 1 and $60 \mathrm{kHz}$.

The input power increases with the applied voltage amplitude and frequency. It has to be underlined that large aerosol modifies the plasma characteristics and that input power is thus not relevant to deal with aerosol filtration. Once the Di-Ethyl-Hexyl-Sebacate (DEHS) droplets are injected the current pulse are smaller and last longer than without aerosol probably due to the modification of the gas composition (the aerosol generator used to produce DEHS droplets also produces $\mathrm{CO}$ and $\mathrm{CO}_{2}$ from DEHS heating at $300^{\circ} \mathrm{C}$ ). Moreover, in the case of the cordierite filter, the DEHS collection on the walls implies surface conduction losses. The mean current of discharge $\left(I_{d}\right)$ is thus defined as the sum of the impulsive charge per unit time, and is calculated according to:

$$
I_{d}=\frac{1}{n T} \cdot \sum_{i}\left|Q p_{i}\right|
$$

where $Q p_{i}$ is the charge of the $\mathrm{i}^{\text {th }}$ pulse during $n T$.

The thermal characterisations of the DBD filters have already been presented in [22]. At quasi steady state, the mean temperature of the dielectric surface is controlled, at first order, by surface power density $\left(\mathrm{W} . \mathrm{m}^{-2}\right)$, the area of the electrode and the output heat exchanges. The temperature of the dielectric surface is close to ambient temperature bellow $2 \mathrm{kHz}$ and reaches $200{ }^{\circ} \mathrm{C}$ at $60 \mathrm{kHz}$.

\subsection{Aerosol generation and characterization}

The study of aerosol collection in DBD is conducted in clean (i.e. without volatile organic compound contamination), dry air (relative humidity below 5\%). The face area of the filters is $0.1 \mathrm{~cm}^{2}$. The gas flow rate injected in the filters was adjusted between 0.25 and $6 \mathrm{~L} \mathrm{~min}^{-1}$ by mass flow controllers (Brooks model 5850E ); leading to transit time and gas velocity in the filter between $160,7 \mathrm{~ms}$ and $0.18,4.32 \mathrm{~m} \mathrm{~s}^{-1}$ respectively. From calculations, the flow regime is laminar up to $8 \mathrm{~L} \cdot \mathrm{min}^{-1}$.

\subsubsection{Aerosol generators}

In order to characterise precisely the efficiency of the filter, monodisperse aerosol is produced with controlled size $d_{\mathrm{p}}$, flow rate $Q_{\mathrm{p}}$ and concentration $N_{p}$. Two aerosol generators were used in this study:

- a nebuliser (model $\mathrm{TSI}^{\circledR} 3076$ with $0.05 \mathrm{~g} \mathrm{NaCl}$ per liter) associated with a dryer to produce unimodal $\mathrm{NaCl}$ aerosol centred on $40 \mathrm{~nm}$. 
- a Sinclair Lamer Generator (Topaz ${ }^{\circledR}$ model SLG 270) to produce a liquid aerosol of DEHS by nebulisation of a $\mathrm{NaCl}$ solution, followed by heterogeneous condensation of DEHS on the dry $\mathrm{NaCl}$ residues. The nucleation occurs in a saturator, which controls the temperature and thus the final size of the particle.

The main characteristics of the test aerosols so-produced are summarised in Table 1.

\begin{tabular}{|c|c|c|c|c|c|}
\hline Generator & Principle & $\mathrm{d}_{\mathrm{p}}(\mathrm{nm})$ & $\begin{array}{c}\mathrm{Q}_{\mathrm{p}} \\
(\mathrm{lpm})\end{array}$ & $\mathrm{N}_{\mathrm{p}}\left(\mathrm{cm}^{-3}\right)$ & $\sigma_{\mathrm{g}}$ \\
\hline Nebuliser & Nebulisation & $30-100$ & $0.25-5$ & $10^{6}$ & $1.12-1.14$ \\
\hline SLG & $\begin{array}{c}\text { Heterogeneous } \\
\text { condensation }\end{array}$ & $300-1200$ & $0.25-5$ & $10^{5}-10^{8}$ & $1.1-1.15$ \\
\hline
\end{tabular}

Table 1. Main characteristics of the generator used in this study; values correspond to range used here.

When the aerosol produced is not monodisperse (Nebuliser), a differential mobility analyser (DMA model TSI ${ }^{\circledR}$ 3071) is used to select particles in a narrow size range using the particle electrical mobility that depends on particle size (cf. Fig. 3a). Particles get charged, classified and the selected fraction is neutralized (using a Kripton-85 neutralizer model TSI ${ }^{\circledR}$ 3077 and an electrostatic precipitator to remove the remaining charged fraction) before injection in the DBD filter. Fig. 4 represents the particle size distribution of the monodisperse aerosol produced by the nebuliser after selection (a) and by SLG (b).
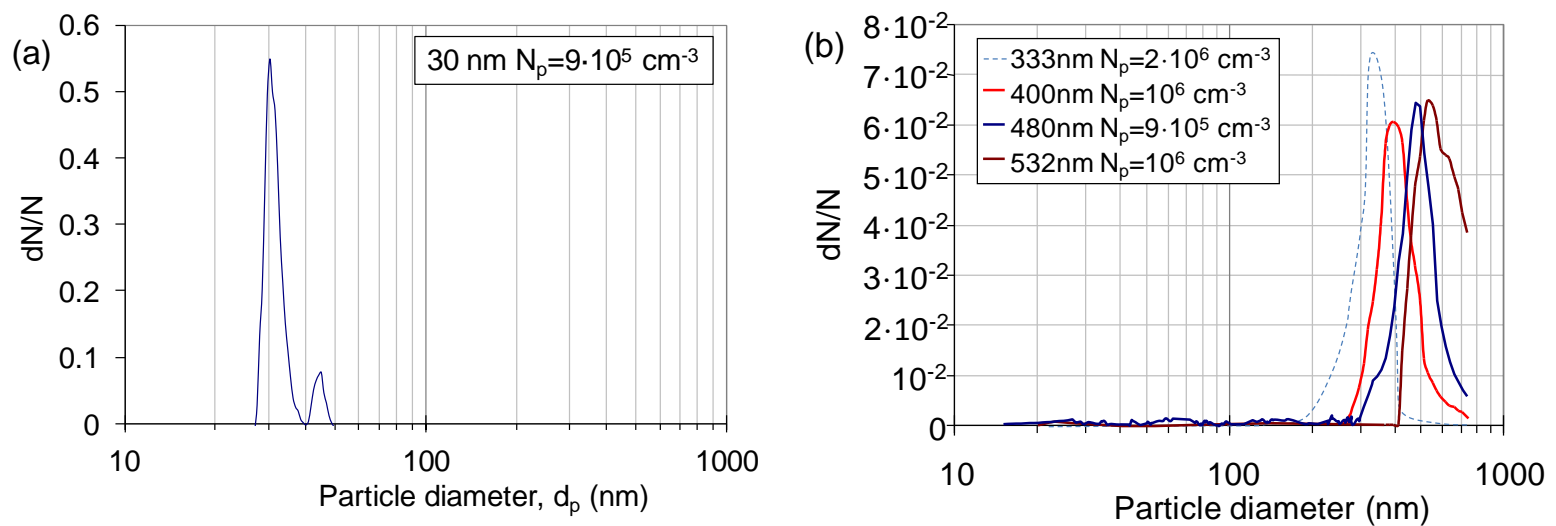

Fig. 4. Size distribution of monodisperse aerosol produced by (a) Nebuliser with DMA (b) SLG.

The main peak in Fig. 3(a) has a mode of $30 \mathrm{~nm}$, the size is controlled by the voltage applied on the DMA. The small peak is related to initially doubly charged particle of $42 \mathrm{~nm}$ which had the same electrical mobility as that of singly charged $30 \mathrm{~nm}$ particle $\left(2.5 \cdot 10^{-7} \mathrm{~m}^{2}\right.$ $\mathrm{V}^{-1} \mathrm{~s}^{-1}$ ) and the entrance of the DMA. In Fig. 3b, four size distributions are presented. The size of the particle is controlled by the temperature of the DEHS saturator.

All the aerosols produced are neutralized with a Kripton- 85 neutralizer before injection in the DBD filter.

\subsubsection{Aerosol and filtration efficiency characterizations}

Aerosol concentration can be given in number, surface or mass of particle per cubic unit gas volume $\left(\mathrm{m}^{-3}\right)$. In filtration the most commonly use is mass concentration. Nevertheless, in aerosol physics and in this paper, the number concentration (hereafter referred as concentration) is used to deal with the physical processes of aerosol charging, collection and resuspension/cleaning.

The aerosol particle concentrations downstream the DBD filters were measured with a condensation particle counter (CPC model $\mathrm{TSI}^{\circledR}$ 3022A). The CPC counts particles from 
0.005 to $3 \mu \mathrm{m}$ using the principle of light scattering after growth by heterogeneous condensation of butanol.

With a clean filter, in clean gases (without aerosol nor VOC in the gas injected in the DBD filter), ultrafine particles (mode at 2-3 nm) are produced from the interaction of filament with dielectric surface [4], the concentrations of particle measured with CPC (above $5 \mathrm{~nm}$ ) is below $1 \mathrm{~cm}^{-3}$. These particles are highly diffusive and can easily be removed downstream the DBD filter by Brownian diffusion on the tube wall.

The size distributions of the particles were obtained by two methods. With a differential mobility analyser (DMA), the particles are neutralized with a Kripton- 85 neutralizer $\left(\mathrm{Kr}^{85}\right)$, classified by the DMA and counted with the CPC. An optical particle counter (PCS 2010 from Palas Inc.) measures the size distribution of particles with diameters $\left(d_{p}\right)$ larger than $270 \mathrm{~nm}$ based on light scattering measurements.

The efficiency of filtration is defined as $100 *\left(N_{p o}-N_{p}\right) / N_{p o}$ where $N_{p o}$ is the initial output concentration without applied voltage and $\mathrm{N}_{\mathrm{p}}$ is the output concentration. The mass filtration efficiency is calculated in the same way, using mass concentration instead of number concentration. The filtration efficiency is thus only related to electrostatic losses and do not include diffusion losses (the diffusion losses are negligible in the transit time involved 7$160 \mathrm{~ms})$.

At last, chemical analysis of gaseous species (ozone, nitrogen oxides, and carbon oxides) produced by the discharge are performed by infra-red spectroscopy using a $20 \mathrm{~cm}$ optical path cell and an absorption spectrometer (Brucker ${ }^{\circledR}$ model vector 22). Gaseous effluents are blown out from the discharge in the analysis cell, with a transit time in the second range.

The filtration efficiency is presented in Fig. 5 for the cordierite DBD filter with a peak-topeak applied voltage of $20 \mathrm{kV}$ at a frequency of $1 \mathrm{kHz}$ with a gas flow rate of $0.25 \mathrm{~L} \mathrm{~min}^{-1}$ of DEHS particle with a diameter of $400 \mathrm{~nm}$ versus aerosol concentration between $9 \cdot 10^{5}$ and $10^{8} \mathrm{~cm}^{-3}$.

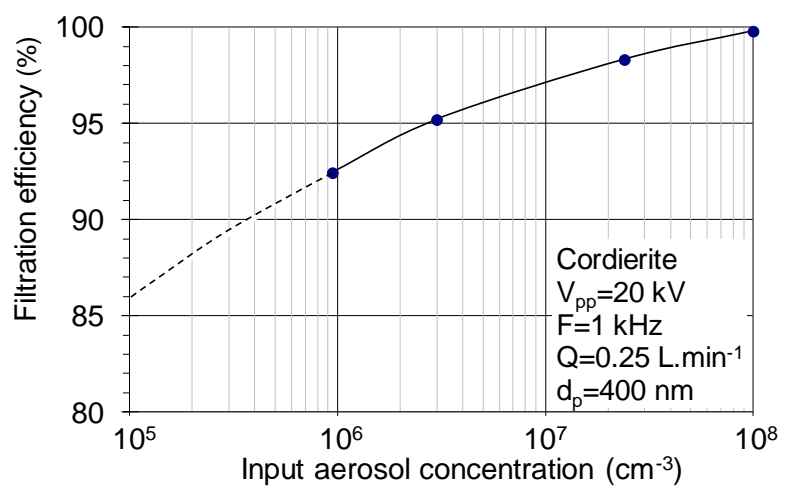

Fig. 5. Filtration efficiencies versus aerosol concentration for $400 \mathrm{~nm}$ DEHS particle.

As in most filtration processes, the filtration efficiency for a given monodisperse aerosol depends on the aerosol concentration [23]. The filtration efficiency varies from $92 \%$ at $9 \cdot 10^{5} \mathrm{~cm}^{-3}$ to $99.8 \%$ at $10^{8} \mathrm{~cm}^{-3}$ for a facial filtration surface area of $0.1 \mathrm{~cm}^{2}$ with a gas velocity of $0.18 \mathrm{~m} \mathrm{~s}^{-1}$ leading to a transit time of $160 \mathrm{~ms}$ in the DBD filter. In the following, the filtration efficiencies for monodisperse aerosol of different size are thus compared at the same concentration. 


\section{Experimental results}

The first part of this section deals with the aerosol filtration efficiency in the DBD filters, the second one with the charge and the electro-collection efficiencies and the third one with the cleaning of the DBD filters.

\subsection{Aerosol filtration efficiency at low frequency}

The fractional filtration efficiency (filtration efficiency versus diameter for a polymodal aerosol with one mode at $100 \mathrm{~nm}$ and the second at $400 \mathrm{~nm}$ ) of the DBD filter has been investigated with a total concentration of $10^{6} \mathrm{~cm}^{-3}$. The mean number and mass filtration efficiencies reach $87 \%$ and $95 \%$, respectively. These values are similar than those of classical fibrous filter.

Filtration efficiencies hereafter refer to number efficiencies for each diameter of monodisperse aerosol. Moreover, as the filtration efficiency depends on aerosol concentration (cf. Fig. 5) the filtration efficiency is presented for the same concentration rather than the classical fractional efficiency as defined in [1].

An aerosol of $400 \mathrm{~nm}$ monodisperse DEHS droplets with a concentration of $10^{6} \mathrm{~cm}^{-3}$ is used as a reference test in the most penetrating particle size range (MPPS [0.1-0.7] $\mu \mathrm{m}$, cf. \$3.2.2.). The temporal evolution of filtration efficiency for the $400 \mathrm{~nm}$ monodisperse DEHS droplets is presented (full line in Fig. 6) for the cordierite filter with a peak-to-peak voltage of $15 \mathrm{kV}$ at $1 \mathrm{kHz}$. The mean discharge current (dot line) is also presented. At $t=0$, the DBD filter is off and the aerosol is injected in the filter. The DBD is switched on at $t=1 \mathrm{~min}$.

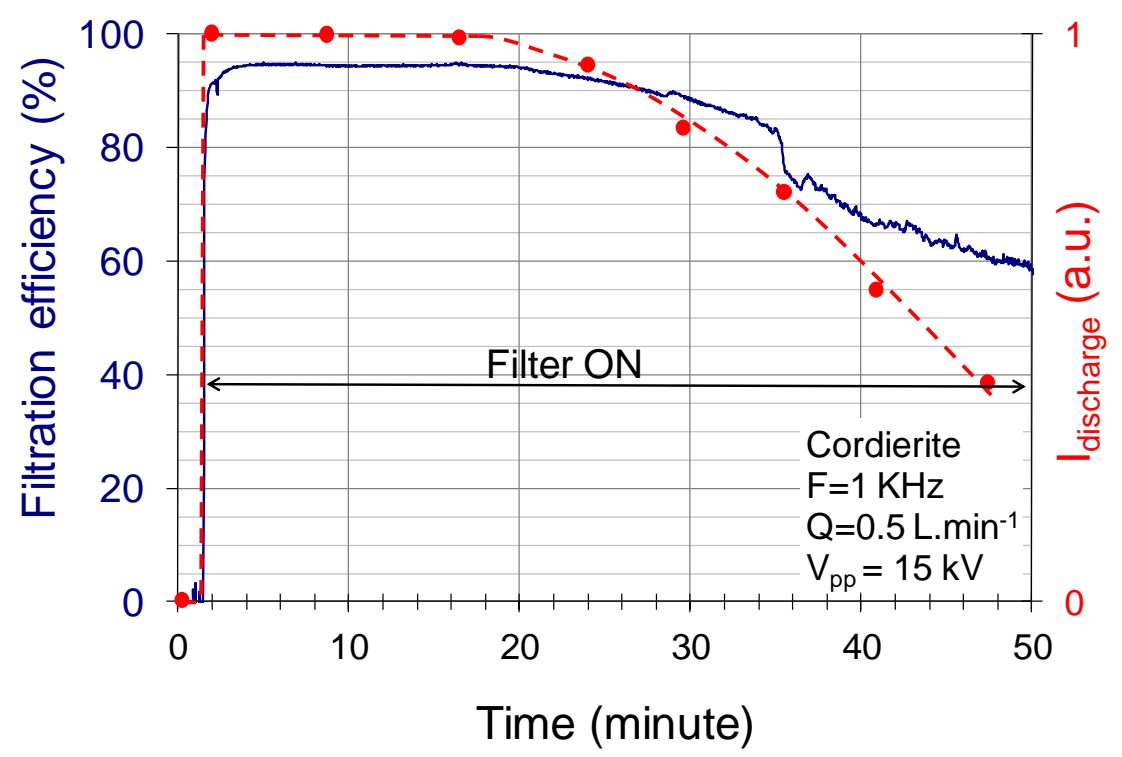

Fig. 6. Aerosol filtration efficiency and discharge current versus time.

One minute after the DBD is turned on, the filtration efficiency reaches $95 \%$ during 20 minutes proving that the filter operates properly. The electro-collection of aerosol in DBD filter is based on two steps: the first one is the charge of aerosol by collection of ion and the second is the collection on the dielectric surfaces inside the filter due to electrostatic forces.

Those mechanisms are known and have already been presented in [24, 25]. The reduction of filtration efficiency related to the reduction of discharge current is detailed in §3.2.2. 


\subsection{Charge and electro-collection at low frequency (below $10 \mathrm{kHz}$ )}

The filtration efficiency is related to the efficiencies of aerosol charging and electrocollection.

The electro-collection of charged aerosol has been studied in [25]. The kinematics of a charged particle depends on the particle electrical mobility (related on particle size and charge level) and the electric field. In DBD, the charge level of a particle evolves depending on the ion density met by the particle. Aerosol charging and kinematics are thus coupled [11, 13, 24, 26]. High applied voltage, low frequency and small gap length are favourable for the electrocollection. To prevent from clogging, to limit the pressure drop and to ensure the gap length homogeneity in the entire filter, millimetre gaps are best suited. A compromise has been chosen with a gap of $1 \mathrm{~mm}$ for peak-to-peak applied voltage between 13 and $20 \mathrm{kV}$ at $1 \mathrm{kHz}$.

\subsubsection{Versus hydrodynamic parameters}

In the gas flow range from 0.25 to $6 \mathrm{~L} \mathrm{~min}^{-1}$, the flow regime in the DBD filter is laminar. If the filamentary discharges can induce local electric wind and gas turbulences, this effect can be neglected at low frequency $[11,24]$.

The charging time in DBD is about 5 times the voltage period, as long as the number of filaments per time and surface unit is higher than 20 per half-period and square centimetre. In fact, longer transit times (for smaller gas flow rate or longer electrodes) do not affect the filtration efficiency more than $10 \%$ and subsequent electro-collection occurs in less than a period. Hence, the charging time in the transient ion density of DBD is of a few periods (about $0.15 \mathrm{~ms}$ ) to reach similar mean charging conditions.

From these results, a 10 stages DBD filter (10 single DBD filters in parallel) has been developed to prove the feasibility of the filtration at $60 \mathrm{~L} \cdot \mathrm{min}^{-1}$ with a facial surface area of square centimetres and a power consumption of 7.4 Watt to reach a filtration efficiency of $84 \%$ in the MPPS at $0.4 \mu \mathrm{m}$ for an aerosol concentration of $5 \cdot 10^{6} \mathrm{~cm}^{-3}$.

\subsubsection{Versus aerosol parameters}

Three aerosol parameters have been investigated. The influence of aerosol concentration has already been presented in $\$ 2.2 .2$. The influence of aerosol nature is presented in $\S 4.2$. The particle size is the most critical parameter presented just below.

Fig. 7 represents the filtration efficiencies versus monodisperse aerosol diameter between 30 and $900 \mathrm{~nm}$ for the cordierite and alumina DBD filters with a peak-to-peak applied voltage of $20 \mathrm{kV}$ at a frequency of $1 \mathrm{kHz}$. The monodisperse aerosol is either $\mathrm{NaCl}$ crystal $(20,30$, $100 \mathrm{~nm}$ ) or DEHS droplets (monodisperse 300, 400, $900 \mathrm{~nm}$ and unimodal $1.2 \mu \mathrm{m}$ ) with a constant concentration of $10^{6} \mathrm{~cm}^{-3}$ for a gas flow rate of $0.25 \mathrm{~L} \mathrm{~min}^{-1}$.

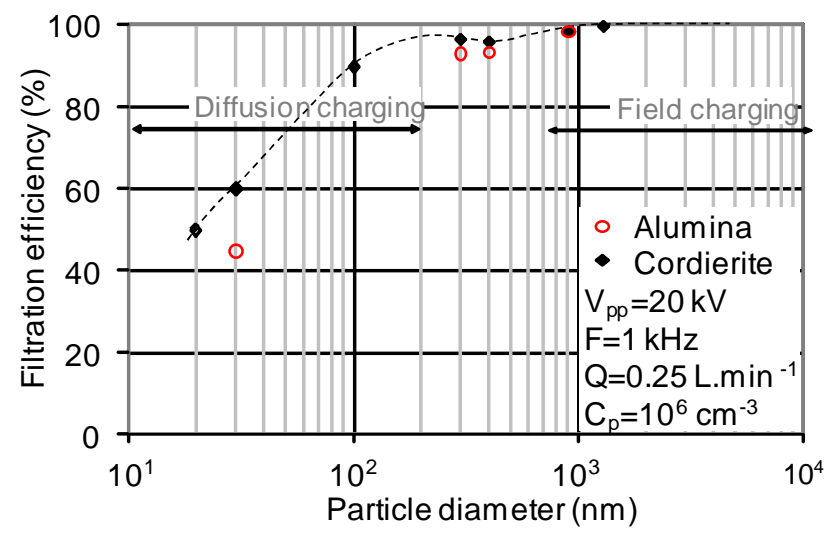

Fig. 7. Particle filtration efficiencies versus aerosol diameter for different monodisperse aerosol at $10^{6} \mathrm{~cm}^{-3}$ for cordierite and alumina filters. 
With the short transit time (below $160 \mathrm{~ms}$ ) in DBD, fine particles (below $100 \mathrm{~nm}$ ) are hardly filtered by electro-collection due to the small fraction of charged particles. However, the ultrafine fraction is highly diffusive and can easily be removed with long transit time of a few tens of seconds. For particles larger than $100 \mathrm{~nm}$, all particles are charged and the filtration efficiency is higher than $90 \%$. These values are similar to classical fibrous filters [2]. The efficiency remains higher than $90 \%$ even in the 100-700 $\mathrm{nm}$ range. In this most penetrating particle size range (MPPS), both field and diffusion charging mechanisms are less efficient which implies that particles in this size range are the most difficult to filter.

The alumina filter gives the same results except for fine particles. The cordierite filter is more efficient for fine particles probably due to a higher surface of collection by diffusion for cordierite with walls in the gap than for the plane-to-plane alumina filter.

\subsubsection{Versus plasma parameters}

Optimal plasma conditions for aerosol charging: in the conditions specified in \$3.2.2 (residence time higher than 5 voltage periods and filament density higher than 20 per half period and per $\mathrm{cm}^{2}$ ), the reduction of the gap length is favourable in terms of aerosol charging at constant mean current of filament $\left(\mathrm{I}_{\mathrm{d}}\right)$. Less energetic but more numerous filaments lead to higher charge level per particle then for larger gap width. Nevertheless, a $1 \mathrm{~mm}$ gap has been chosen for the reasons specified in $\S 3.2$.

The influence of filament distribution in time and space has also been studied. The increase of the mean discharge current by an increase of the frequency at constant applied voltage or reversely leads to higher charge level.

At constant mean discharge current, the increase of the frequency at reduced voltage leads to higher charge level. Thus, a smaller number of filaments per period compensated by higher frequency is favourable for aerosol charging. For $400 \mathrm{~nm}$ particle, the increases of frequency from 0.75 to $1 \mathrm{kHz}$ at $I_{d}=0.7 \mu \mathrm{A}$ and from 1 to $9 \mathrm{kHz}$ at $I_{d}=14 \mu \mathrm{A}$ lead to higher mean charge level from 95 to 120 and from 132 to 140 respectively.

Optimal plasma conditions for aerosol electro-collection: high-applied voltage, low frequency and small gap length are favourable for the electro-collection. If the charge level of aerosol increases with frequency, the electro-collection decreases. Hence, there is an optimal frequency for filtration including both charging and electro-collection around $1 \mathrm{kHz}$ in millimetre gap DBD (cf. Fig. 8a).

\section{Optimal plasma conditions for aerosol filtration}

The filtration is thus performed at low frequency $(1 \mathrm{kHz})$, maximal voltage $(20 \mathrm{kV}$ peakto-peak), with transit time longer than 5 voltage periods. The increase of the applied voltage is favourable for both aerosol charging (increase of the charge level per particle) and electrocollection, as detailed above.

Particle filtration efficiencies are plotted for an aerosol flow rate of $0.5 \mathrm{~L} \mathrm{~min}^{-1}$ with DEHS droplet of $400 \mathrm{~nm}$ at $10^{6} \mathrm{~cm}^{-3}$ versus the frequency for alumina filter (Fig. 8a) and versus the density of discharge current $\left(J_{d}=I_{d} / S\right.$, with $S$ the area of the metal electrodes $)$ for the cordierite filter at $1 \mathrm{kHz}$ (Fig. 8b). 

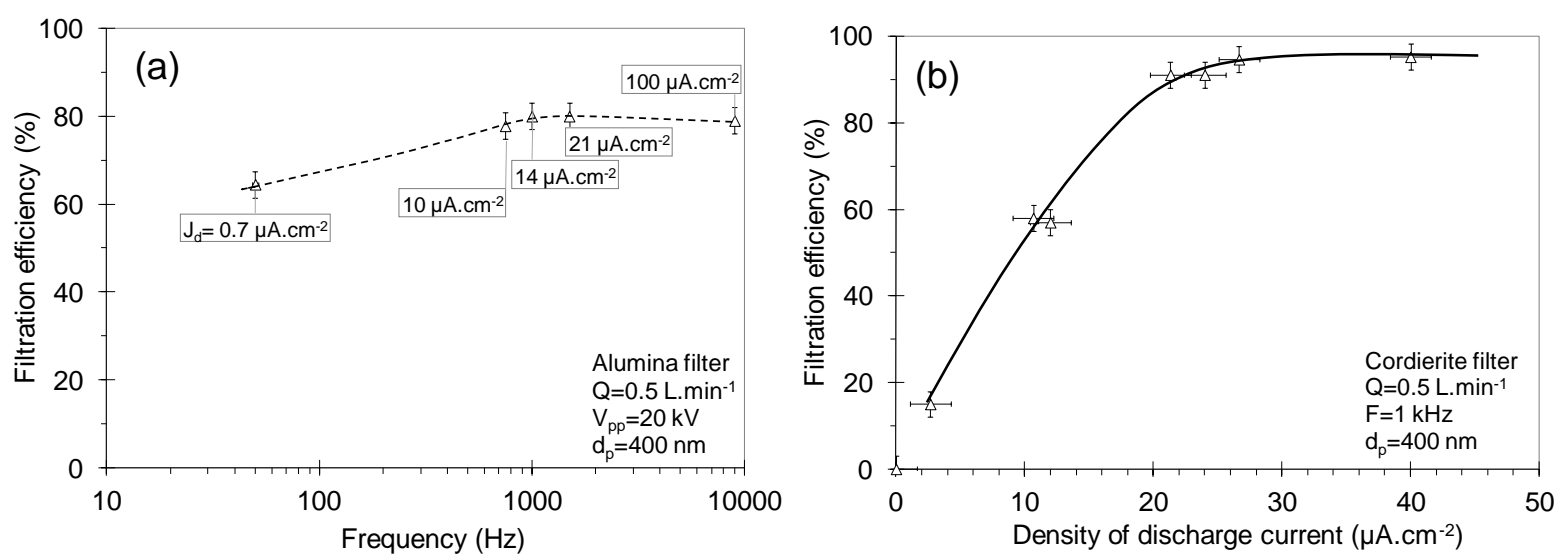

Fig. 8. Filtration efficiency versus (a) the frequency $(\mathrm{Hz})(\mathrm{b})$ the density of discharge current $\left(\mu \mathrm{A} \mathrm{cm} \mathrm{cm}^{-2}\right)$ for the MPPS of $400 \mathrm{~nm}$.

In Fig. 8(b), the initial filtration efficiency in clean filter increases with the applied voltage and therefore with $J_{d}$ up to $95 \%$ for $400 \mathrm{~nm}$ particle at $18-20 \mathrm{kV}$ peak-to-peak voltage is. Since all particles are charged in this size range, the $5 \%$ of non-collected aerosol probably concerns particle injected at the centre of the gap that never reaches the collecting surfaces due to an electrical mobility too weak for the collection in the drift time (half a period) and/or to local turbulences around each filament. The reduction of the gap is one way to increase the collecting efficiency. In a given arrangement, the mean current of discharge $\left(I_{d}\right)$ is the most critical parameter that controls the filtration efficiency. The curve in Fig. 8(b) is still valid when the filter is loaded and that the discharge current decreases as detailed bellow.

Temporal stability and filter loading: at the beginning of the filtration step, there is a plateau of maximum filtration efficiency lasting between 5 and 90 minutes depending on the mean discharge current and on the loading rate (cf. Fig 6). After this plateau, the filtration efficiency decreases.

The loading rate per surface unit $\left(\mathrm{kg} \mathrm{h}^{-1} \mathrm{~m}^{-2}\right)$ is the product of aerosol mass concentration $\left(\mathrm{kg} \cdot \mathrm{m}^{-3}\right)$, by filtration efficiency, by aerosol flow rate $\left(\mathrm{m}^{3} \mathrm{~s}^{-1}\right)$, divided by the area of the collecting surface $\left(\mathrm{m}^{2}\right)$. The loading threshold before the reduction of filtration efficiency is about $30 \mathrm{mg} \mathrm{cm}^{-2}$ for a $20 \mathrm{kV}$ peak-to-peak voltage, with DEHS droplets, whatever the size is. The deposited mass leads to the decrease of the mean discharge current. This effect is probably due to the increase of the specific capacitance ( $\varepsilon / \mathrm{e}$, with $\varepsilon$ the dielectric permittivity, e the dielectric thickness) arising from the collection of liquid DEHS particles. The increase of the specific capacitance leads to a reduction of the Laplace's field (electric field due to the applied voltage). As soon as the filtration efficiency decreases below $80 \%$, the filtration step is stopped and the filter is cleaned as presented in the following section.

\subsection{Filter cleaning}

\subsubsection{Surface cleaning of DBD filter}

After filtration, the cleaning step consists in flushing the filter with clean air (without particle). The evolution of the discharge current during the cleaning step at $750 \mathrm{~Hz}$ and $60 \mathrm{kHz}$ are presented in Fig. 9 (a) and (b) respectively with a $20 \mathrm{kV}$ peak-to-peak voltage for a mass of DEHS deposited at $1 \mathrm{kHz}$ on the dielectric surfaces of a few mg. This collected mass of DEHS of $2 \mathrm{mg}$ for the alumina and $4 \mathrm{mg}$ for the cordierite DBD filters are calculated from the loading rate of $3.4 \cdot 10^{-6} \mathrm{~g} \mathrm{~s}^{-1}$ - during 8 to 16 minutes-, neglecting cleaning during filtration). 
(a)

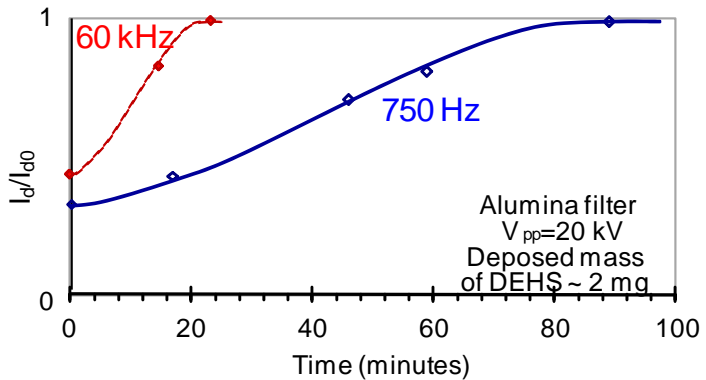

(b)

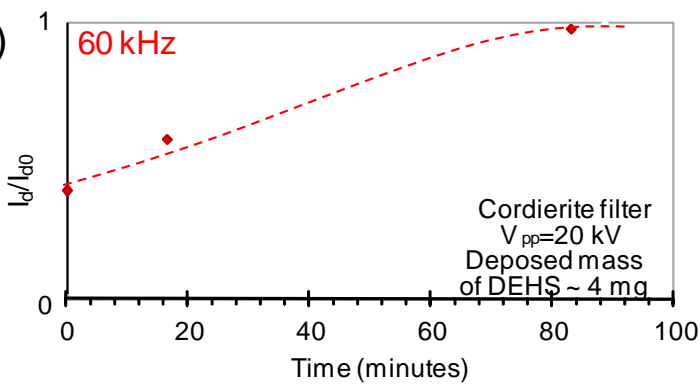

Fig. 9. Evolution of the discharge current during the cleaning step for (a) the alumina filter at $750 \mathrm{~Hz}$ and $60 \mathrm{kHz}(\mathrm{b})$ the cordierite filter at $60 \mathrm{kHz}$.

The mean discharge current increases with time, up to a plateau back to the initial value before the collection of particles on dielectric surfaces. After the cleaning, the filtration efficiency is the same than before loading, which proves that the dielectric surfaces are regenerated and thus that the DBD filter can be cleaned. The cleaning duration is longer for the cordierite filter probably because (i) the porosity of the material is higher than for alumina (ii) the initial mass deposited is higher and (iii) the discharge current is $15 \%$ lower than for the alumina filter.

The cycle of loading and cleaning has been repeated four times with the same conditions and at least 40 times in different operating conditions for the alumina filter. Each time, the discharge current and the filtration efficiency returns to the initial values. Hence, the DBD filter can be cleaned when the filter is loaded with DEHS at both $60 \mathrm{kHz}$ and $750 \mathrm{~Hz}$.

Contrary to organic aerosol, $\mathrm{NaCl}$ particle are only removed at high frequency, when the cleaning step occurs at $60 \mathrm{kHz}$. The mechanisms or filter cleaning are discussed in section 4 .

\subsubsection{Cleaning duration versus collected mass and discharge parameters}

At low frequency $(750-5000 \mathrm{~Hz})$ with organic aerosols, the plasma assisted combustion is active. Indeed, after cleaning, the discharge current and the filtration efficiency return to the initial values before particles collection proving that dielectric surfaces has been cleaned. The cleaning duration depends on the mass of particles deposited on the surfaces and the mean current of discharge during the cleaning step. The cleaning duration varies from 1.5 to 3 times the filtration duration. With the same power supply, the aerosol can be filtered and the filter cleaned at constant frequency.

To sum up, alumina and cordierite DBD filters are maintenance-free since they can be cleaned to return to initial filtration efficiency. Indeed, as discussed below, in these working conditions, DBD are long life systems (still working in the same conditions after two PhD).

\section{Discussions}

This last section is devoted to the key-points of this work: the production of fine particle by filament-surface interaction, the mechanisms of filter cleaning, and maintenance-free of DBD filters.

\subsection{Fine particles production during the filtration of liquid/solid collected aerosol}

\subsubsection{Effect of dielectric material porosity during the collection of liquid/solid aerosol}

For solid aerosol, both alumina and cordierite filters leads to similar results for particles larger than $100 \mathrm{~nm}$.

For liquid aerosol in the alumina filter for $400 \mathrm{~nm}$ DEHS droplets, the decrease of aerosol filtration efficiency is associated with the detection of fine particles downstream the filter. 
Fine particles smaller than $270 \mathrm{~nm}$ (detected only by CPC and not by PCS) are produced either by the interaction of filament with the liquid film on the surface or by the electrospraying of the liquid film in high electric field (above $10^{6} \mathrm{~V} \cdot \mathrm{m}^{-1}$ ) as already depicted in DC electro-precipitator [27].

In the case of the cordierite filter, no fine particles are detected downstream the filter. This may be due to the porosity of the cordierite. The liquid can enter the pores preventing the production of ultrafine particles. The loading of the surface leads to a decrease in filtration efficiency associated with a reduction of $I_{d} u p$ to the extinction of the discharge in the case of cordierite but without any production of fine particles (cf. Fig. 6). The re-ignition of the discharge thus requires an increase of the applied voltage. This effect is probably due to the increase of the specific capacitance arising from the collection of liquid DEHS as described in the paragraph temporal stability of section 3.2.3.

From these results, it is now possible to size a DBD filter depending on the nature of aerosol to be filtered. If the aerosol to be filtered is known and constant, a specific dielectric material should be used. For instance, a porous dielectric should be used to filter liquids; walls should be used to filter fine aerosol. If the aerosol is complex with different phase and nature, the association of the two DBD filters with the alumina filter followed by the cordierite filter seems to be the optimal configuration.

\subsubsection{Surface vaporisation by filamentary discharges interactions with surfaces}

Despite ultra-fine primary nanoparticles produced by nucleation subsequent to local surface vaporisation by transient filaments local power density deposited in each spot of interaction on surface $\left(>10^{11} \mathrm{~W} \mathrm{~m}^{2}\right.$ ) with energy density above the fluency threshold of dielectric and electrode materials $\left(0.4>0.1 \mathrm{~J} \mathrm{~cm}^{-2}\right.$ required for vaporisation, [2]). Alumina and cordierite DBD filters are maintenance-free, since they can be cleaned to return to initial filtration efficiency. Indeed, in these working conditions, DBD are long life systems.

It has to be underlined that this ultra-fine aerosol $(<10 \mathrm{~nm})$ produced by filamentary discharges in DBD is not a problem for filtration devices since it is easily collected downstream the filter by diffusion on the walls before injection in the volume to be conditioned.

For catalytic DBD filters impregnated with catalysts, discussed below for the cleaning by low temperature combustion of organic particles collected on surface, surface vaporisation and fouling of surface by collected particle reduce the effective surface of catalyst. Indeed, the catalytic activity is known to decrease with time requiring the replacement of the catalysts.

\subsection{Cleaning mechanisms}

The study of the cleaning has been handled with DBD fed with clean dry air. The different mechanisms of cleaning are discussed for organic and mineral aerosol.

For organic aerosol, such as DEHS, the collected particles are most removed by plasmaassisted combustion as proven by the emission of carbon oxides and water downstream the DBD filter during the filtration step. Those mechanisms are already known and have been used for the treatment of low concentrated volatile organic compound (VOC) at ppm levels $[4,6,28-36]$. At high frequency $(60 \mathrm{kHz})$, the increase of dielectric surface temperature reaches $200^{\circ} \mathrm{C}$ and assists the surface cleaning. Nevertheless, the combustion is not complete. The $\mathrm{CO}$ and $\mathrm{CO}_{2}$ detected only represent between $60 \%$ and $80 \%$ of the total carbon of the collected DEHS. The missing carbon probably arises from gaseous and nanoparticles degradation by-products below the measurement sensibility in the effluent or accumulated on the walls and from the remaining liquid DEHS trapped deeply in cordierite pores.

Adding a catalyst in those processes would increase the energy efficiency and the $\mathrm{CO}_{2}$ selectivity [37-42]. To reach optimal efficiency, a catalyst must work in a given temperature 
range that can be easily controlled in a DBD [22]. At last, the potentialities of plasma assisted combustion to clean reactor is mentioned in [30,43-45]. Few works deal with the removal of both gaseous and particulate pollutant using non thermal plasma [16, 43, 46-49]. However, filamentary discharges with subsequent surface vaporisation would probably reduce the catalytic activity with repeated cleaning phases. Indeed, cleaning is performed at high power density and related surface temperatures to shorten the cleaning duration at higher frequencies. Hence, the use of catalytic DBD may be useful to reach initial faster cleaning but does not seem to be suitable for the self-cleaning maintenance DBD filters. Indeed, decreasing catalytic efficiency due to recurrent filtration and cleaning steps with filamentary DBD, would imply a maintenance step of such catalytic DBD filters.

For mineral aerosol, the filter cleaning has only been observed at high frequency $(60 \mathrm{kHz})$. Fine particles (below $270 \mathrm{~nm}$ ) are detected downstream the filters. The particles are produced nucleation of condensable species formed by vaporisation of the deposited aerosol due to filament interaction as already identified with filamentary discharges [4]. Another process can be involved in the filter cleaning of mineral aerosol, the resuspension of the particle collected on the surfaces by electrostatic forces [50]. At low frequency $(1 \mathrm{kHz})$, if particles are produced, they are smaller than $5 \mathrm{~nm}$ below the detection limit.

\subsection{Maintenance-free DBD filters}

Alumina and cordierite DBD filters are maintenance-free since they can be cleaned to return to initial filtration efficiency. Indeed, as discussed in section 3.3.2, in these working conditions, DBD are long life systems.

If high frequency $(60 \mathrm{kHz})$ cannot be used for filtration due to poor filtration efficiency (related to small particle drift time for collection $<8 \mu \mathrm{s}$ ), higher $\mathrm{I}_{\mathrm{d}}$ and subsequent surface temperatures can be reached that reduce the cleaning duration down to 0.5 times the filtration duration. However, higher power consumption and two filtering and cleaning frequencies are required.

A continuous filtration thus requires several DBD filters operating in parallel. When a DBD is filtering the others are cleaned. When the filtration efficiency decreases below $80 \%$, another filter takes over the filtration. As the cleaning step requires clean air, a small fraction (less than $10 \%$ ) of the air filtered by the other DBD is used. If only one power supply can be used e.g. for embedded filters, the cleaning occurs at low frequency that requires four DBD filters. If two power supplies can be used, the cleaning can operate at high frequency and only two DBD filters are required.

\section{Conclusions}

The development of a reliable aerosol filter without maintenance represents a scientific and technological challenge, which may be solved by using non-thermal plasma. In that respect, dielectric barrier discharge in well-controlled operating conditions can charge and collect aerosol on dielectric surfaces.

When the residence time is higher than 5 periods and the filament density is higher than 20 per half period and per $\mathrm{cm}^{2}$, the particle filtration efficiency depends on the mean discharge current and the diameter of the particles. The filtration efficiency reaches levels identical to those found in classical fibrous filters. The filter loading leads, after a period depending on the initial mean filament current and the mass of deposited aerosol, to the decrease of the filament mean current and the related filtration efficiency. This parameter can be used to identify when the filter has to be cleaned. 
When the surface is fouled with liquid, the porosity of the dielectric surface is critical. With a smooth dielectric surface, fine particles are produced, whereas with a porous dielectric material, such as cordierite, there are no fine particles produced.

The feasibility of the filter cleaning by plasma-assisted combustion with filamentary discharge has been achieved with organic aerosol. Indeed, after cleaning, the discharge current and the filtration efficiency return to the initial values before particles collection, proving that dielectric surfaces has been cleaned. Operating frequency can be increased to reduce the cleaning duration leading to a compact, long life stable filter. Even mineral aerosol can be removed from the surface at high frequency and the mechanism of cleaning still deserves further investigations.

Several parallel lines with DBD filters permit a continuous filtration. When a DBD is filtering, the others are cleaned. When the filtration efficiency decreases below 80\%, another filter takes over the filtration. DBD filters are thus maintenance-free. Reliable filtration of any aerosol are achieved, whatever the size distribution and composition are with the association of alumina DBD followed by a cordierite DBD.

\section{References}

[1] R.C. Brown, Air filtration: An Integrated Approach to the Theory and Applications of Fibrous Filters, Pergamon Press, New York, 1993.

[2] W.W.-F. Leung, C.-H. Hung, P.-T. Yuen, Experimental Investigation on Continuous Filtration of Sub-Micron Aerosol by Filter Composed of Dual-Layers Including a Nanofiber Layer, Aerosol Science and Technology, 43 (2009) 1174-1183.

[3] A. Jaworek, A. Krupa, T. Czech, Modern electrostatic devices and methods for exhaust gas cleaning: A brief review, Journal of Electrostatics, 65 (2007) 133-155.

[4] J.P. Borra, Nucleation and aerosol processing in atmospheric pressure electrical discharges: powders production, coatings and filtration, Journal of Physics D: Applied Physics, 39 (2006) R19-R54.

[5] U. Kogelschatz, Dielectric-barrier discharges: Their history, discharge physics, and industrial applications, Plasma Chem. Plasma Process., 23 (2003) 1-46.

[6] T. Hammer, Application of plasma technology in environmental techniques, Contrib. Plasma Phys., 39 (1999) 441-462.

[7] B. Eliasson, U. Kogelschatz, Nonequilibrium volume plasma chemical processing, IEEE Trans. Plasma Sci., 19 (1991) 1063-1077.

[8] V.I. Gibalov, G.J. Pietsch, The development of dielectric barrier discharges in gas gaps and on surfaces, Journal of Physics D: Applied Physics, 33 (2000) 2618-2636.

[9] K.V. Kozlov, H.E. Wagner, R. Brandenburg, P. Michel, Spatio-temporally resolved spectroscopic diagnostics of the barrier discharge in air at atmospheric pressure, Journal of Physics D-Applied Physics, 34 (2001) 3164-3176.

[10] J.H. Byeon, J.H. Ji, J.H. Park, K.Y. Yoon, J. Hwang, Charge distributions of aerosol dioctyl sebacate particles charged in a dielectric barrier discharger, Journal of Aerosol Science, 39 (2008) 460-466.

[11] N. Zouzou, E. Moreau, Effect of a filamentary discharge on the particle trajectory in a plane-to-plane DBD precipitator, Journal of Physics D-Applied Physics, 44 (2010).

[12] S.B. Kwon, T. Fujimoto, Y. Kuga, H. Sakurai, T. Seto, Characteristics of Aerosol Charge Distribution by Surface-Discharge Microplasma Aerosol Charger (SMAC), Aerosol Science and Technology, 39 (2005) 987 - 1001.

[13] J.H. Byeon, J. Hwang, J. Hong Park, K. Young Yoon, B. Ju Ko, S. Hoon Kang, J. Ho Ji, Collection of submicron particles by an electrostatic precipitator using a dielectric barrier discharge, Journal of Aerosol Science, 37 (2006) 1618-1628. 
[14] Y. Kawada, T. Kaneko, T. Ito, J.S. Chang, Simultaneous removal of aerosol particles, NOx and SO2, from incense smokes by a DC electrostatic precipitator with dielectric barrier discharge prechargers, Journal of Physics D: Applied Physics, 35 (2002) 1961-1966.

[15] Y. Kuroda, Y. Kawada, T. Takahashi, Y. Ehara, T. Ito, A. Zukeran, Y. Kono, K. Yasumoto, Effect of electrode shape on discharge current and performance with barrier discharge type electrostatic precipitator, Journal of Electrostatics, 57 (2003) 407-415.

[16] Y. Sano, Y. Kawada, T. Takahashi, Y. Ehara, T. Ito, A. Zukeran, T. Takamatsu, Diesel exhaust particles charged by barrier discharge, Journal of Aerosol Science, 31 (2000) 879880.

[17] E. Bourgeois, N. Jidenko, M. Alonso, J.P. Borra, DBD as a post-discharge bipolar ions source and selective ion-induced nucleation versus ions polarity, Journal of Physics D: Applied Physics, 42 (2009) 205202.

[18] N. Jidenko, J.-P. Borra, Feasibility of self-cleaning filter by dielectric barrier discharge, in: CNRS report, contract $\mathrm{n}^{\circ}$ 041.2063.00, Laboratoire de Physique des Gaz et des Plasmas (CNRS-Université Paris Sud), Gif sur Yvette, 2003.

[19] A. Chirokov, A. Gutsol, A. Fridman, K. Sieber, J. Grace, K. Robinson, Self-organization of microdischarges in dielectric barrier discharge plasma, IEEE Trans. Plasma Sci., 33 (2005) 300-301.

[20] X.D. Xu, M.J. Kushner, Multiple microdischarge dynamics in dielectric barrier discharges, J. Appl. Phys., 84 (1998) 4153-4160.

[21] N. Jidenko, M. Petit, J.P. Borra, Electrical characterization of microdischarges produced by dielectric barrier discharge in dry air at atmospheric pressure, J. Phys D.: Apply Phys, 39 (2006) 281.

[22] N. Jidenko, E. Bourgeois, J.P. Borra, Temperature profiles in filamentary dielectric barrier discharges at atmospheric pressure, Journal of Physics D: Applied Physics, 43 (2010). [23] I. Agranovski, Aerosols: Science and Technology, Wiley-VCH, Weinheim, 2010.

[24] N. Jidenko, J.P. Borra, Kinematics of charged nanometric particles in silent discharges, J. Phys D.: Apply Phys, 38 (2005) 617-620.

[25] N. Jidenko, C. Jimenez, F. Massines, J.P. Borra, Nano-particle size-dependent charging and electro-deposition in dielectric barrier discharges at atmospheric pressure for thin $\mathrm{SiOx}$ film deposition, Journal of Physics D-Applied Physics, 40 (2007) 4155-4163.

[26] J.P. Borra, Charging of aerosol and nucleation in atmospheric pressure electrical discharges, Plasma Physics and Controlled Fusion, 28 (2008) 124036.

[27] J.C.M. Marijnissen, A.M. Mollinger, P.H.W. Vercoulen, The generation of (sub)micron droplets in an electrostatic precipitator by electro-spraying, Journal of Aerosol Science, 24, Supplement 1 (1993) S23-S24.

[28] Y.N. Liu, L. Braci, S. Cavadias, S. Ognier, Post-discharge treatment of air effluents polluted by butyl-mercaptan: the role of nitrate radical, Journal of Physics D-Applied Physics, 448.

[29] B.M. Penetrante, R.M. Brusasco, B.T. Merritt, G.E. Vogtlin, Environmental applications of low-temperature plasmas, Pure Appl. Chem., 71 (1999) 1829-1835.

[30] E.M. Van Veldhuizen, Electrical discharges for environmental purposes NOVA Science Publishers, New York, 2000.

[31] L.A. Rosocha, Nonthermal plasma applications to the environment: Gaseous electronics and power conditioning, IEEE Trans. Plasma Sci., 33 (2005) 129-137.

[32] G.R. Parmar, N.N. Rao, Emerging Control Technologies for Volatile Organic Compounds, Crit. Rev. Environ. Sci. Technol., 39 (2009) 41-78.

[33] J. Chen, J. Yang, H. Pan, Q. Su, Y. Liu, Y. Shi, Abatement of malodorants from pesticide factory in dielectric barrier discharges, Journal of Hazardous Materials, 177 (2010) 908-913. 
[34] C. Klett, S. Touchard, A. Vega, M. Redolfi, X. Duten, K. Hassouni, An experimental and modelling study of acetaldehyde oxidation by an atmospheric non-thermal plasma discharge, Acta Technica, 56 (2011) T43-T55.

[35] H.-H. Kim, Nonthermal Plasma Processing for Air-Pollution Control: A Historical Review, Current Issues, and Future Prospects, Plasma Processes and Polymers, 1 (2004) 91110.

[36] J.P. Borra, N. Jidenko, E. Bourgeois, Atmospheric pressure plasmas for aerosols processes in materials and environment, The European Physical Journal Applied Physics, 47 (2009) 22804.

[37] J. Van Durme, J. Dewulf, C. Leys, H. Van Langenhove, Combining non-thermal plasma with heterogeneous catalysis in waste gas treatment: A review, Appl. Catal. B-Environ., 78 (2008) 324-333.

[38] H.L. Chen, H.M. Lee, S.H. Chen, M.B. Chang, S.J. Yu, S.N. Li, Removal of Volatile Organic Compounds by Single-Stage and Two-Stage Plasma Catalysis Systems: A Review of the Performance Enhancement Mechanisms, Current Status, and Suitable Applications, Environmental Science \& Technology, 43 (2009) 2216-2227.

[39] W.B. Li, J.X. Wang, H. Gong, Catalytic combustion of VOCs on non-noble metal catalysts, Catal. Today, 148 (2009) 81-87.

[40] T. Zhu, Y.D. Wan, J. Li, X.W. He, D.Y. Xu, X.Q. Shu, W.J. Liang, Y.Q. Jin, Volatile organic compounds decomposition using nonthermal plasma coupled with a combination of catalysts, Int. J. Environ. Sci. Technol., 8 (2011) 621-630.

[41] S. Pasquiers, Removal of pollutants by plasma catalytic processes, Eur. Phys. J.-Appl. Phys, 28 (2004) 319-324.

[42] M.J. Kirkpatrick, E. Odic, J.P. Leininger, G. Blanchard, S. Rousseau, X. Glipa, Plasma assisted heterogeneous catalytic oxidation of carbon monoxide and unburned hydrocarbons: Laboratory-scale investigations, Appl. Catal. B-Environ., 106 (2011) 160-166.

[43] H. Hayashi, Y. Takasaki, K. Kawahara, K. Takashima, A. Mizuno, Electrostatic Charging and Precipitation of Diesel Soot, IEEE Trans. Ind. Appl., 47 (2010) 331-335.

[44] J.H. Byeon, J.H. Park, Y.S. Jo, K.Y. Yoon, J. Hwang, Removal of gaseous toluene and submicron aerosol particles using a dielectric barrier discharge reactor, Journal of Hazardous Materials, 175 (2010) 417-422.

[45] S. Sato, K. Hensel, H. Hayashi, K. Takashima, A. Mizuno, Honeycomb discharge for diesel exhaust cleaning, Journal of Electrostatics, 67 (2009) 77-83.

[46] D. Ye, D. Gao, G. Yu, X. Shen, F. Gu, An investigation of the treatment of particulate matter from gasoline engine exhaust using non-thermal plasma, Journal of Hazardous Materials, 127 (2005) 149-155.

[47] J.S. Clements, A. Mizuno, W.C. Finney, R.H. Davis, Combined removal of SO2, NOX, and fly-ash from simulated flue-gas using pulsed streamer corona, IEEE Trans. Ind. Appl., 25 (1989) 62-69.

[48] A. Mizuno, Y. Kisanuki, M. Noguchi, S. Katsura, S.H. Lee, U.K. Hong, S.Y. Shin, J.H. Kang, Indoor air cleaning using a pulsed discharge plasma, IEEE Trans. Ind. Appl., 35 (1999) 1284-1288.

[49] L. Parissi, A. Goldman, M. Goldman, E. Odic, J.P. Borra, Temperature effects in cold plasmas. Application to VOC removal from flue gases by dielectric barrier discharges, in: E.M.v. Veldhuizen (Ed.) Electrical discharges for environmental purposes: fundamentals and applications, NOVA Science Publishers, New York, 1999, pp. 279-312.

[50] P. Atten, H.L. Pang, J.L. Reboud, Study of Dust Removal by Standing-Wave Electric Curtain for Application to Solar Cells on Mars, IEEE Trans. Ind. Appl., 45 (2009) 75-86. 